\title{
MODEL ATMOSPHERES FOR VERY COOL HYDROGEN-RICH WHITE DWARFS
}

\author{
France C. Allard \\ Ralner Wehrse \\ Instltut $\mathrm{f}$. Theoret. Astrophysik der Universitat \\ Im Neuenhe1mer Feld 561, D 6900 Heldelberg
}

\section{Introduction}

In recent years c00l white dwarfs have been studied for varlous aspects ( see e.g. Winget et al.,1987 Winget and van Horn, 1987, Koester, 1987, Liebert, 1980) and much effort has been invested in attempts to interpret the energy distributions of these stars (Greenstein, 1984, Ze1dler-K.T. et al, 1986, Llebert et al., 1987, and others). However, it seems that in spite of these efforts the spectra in particular of the very cool objects with effective temperatures below about $6000 \mathrm{~K}$ are not yet fully understood, since they are extremely diverse and each objects needs special consideration. In addition, the analyses are extremely difficult because the principal constiuents of the atmospheres ( $\mathrm{H}, \mathrm{He})$ and elements, which may donate the majority of electrons, are essentialiy invisible. Since usually only one lonisation stage of an element is present, this implies that the gas pressure $\mathrm{P}_{\mathrm{g}}$ is high (compared e.g. to the solar photosphere), the accurate value of $\mathrm{P}_{\mathrm{g}}$, however, cannot be determined reliably.

Simliarly, the red dwarfs and subdwarfs exhibit spectra with very different line blanketing, e.g. the Na D lines of $G 5-22$ and $G 1388$ differ in their equivalent widths by more than than a factor of ten ( Allard et al., in preparation). It should be noted that the gas pressures in these stars and the white dwarfs may be roughly similar since increases in temperature and gravity change $\mathrm{P}_{\mathbf{g}}$ in opposite directions.

Since for $M$ (sub-) dwarfs the spectral differences must due to changes in gravities, effective temperatures, and metal abundances, but not in the hydrogen to hellum rat10, we have started a large project to investigate the possible spectral appearances of hydrogen-rich atmospheres with low temperatures and high gravitles. It is a speclal alm to find out to what extent the spectra of the very cool whlte dwarfs can be understood by means of hydrogen-rlch atmospheres only. For this purpose we have calculated a grld of hydrogen-rlch atmospheres for both very cool white dwarfs and red dwarfs. In this paper we report first results of this investigation. 
In the next section we describe the construction of the atmospher1c models. The1r bas $1 \mathrm{c}$ properties and the resulting energy distributions are briefly discussed in the final chapter III.

\section{Model Construction}

We have calculated models with the following ranges of parameters: $T_{e f f}=$ $3500,4000,5000,6000 \mathrm{~K}, \log \mathrm{g}=5,7,8,[\mathrm{Fe} / \mathrm{H}]=-2,-4,-6$. The relative abundances of the metals and the $\mathrm{He} / \mathrm{H}$ rat 10 are assumed to be solar. In addition, a few models with $\mathrm{T}_{\text {eff }}=3000$ and $2800 \mathrm{~K}$, with $\log \mathrm{g}=9$ and with solar abundances have been computed.

They are calculated with a revised and updated version of the program previously used for white dwarf atmospheres (Wehrse, 1975, Liebert et al. . 1987 ). The basic assumptions (hydrostatic and local thermodynamic equilibrlum, energy transport by radiation and convection, are kept. Major modifications refer to

(1) a new equation of state. The routines are now able to handle flexibly a very large number of species ( the number is effectively limited only by the avallability of the nessary spectroscopic data and by the computer time the user is wllling to spend for the solution of the non-linear system of equilibrlum and balance equations);

(11) checks for the applicability of the impact approximation in all calls for metal line profiles. If a test is negative, the Volgt function is replaced by the quasi-static profile function ( Traving, 1960);

(111) the use of continuum absorption cross-sections from the compllation by Mathisen ( 1984 ) replacing some older approximations;

(1v) the consideration of various molecular bands (cf. Wehrse, 1981 ).

Since we are consldering metal poor models mainly and since due to the high pressures hardly show up in the spectra we have taken into account only 50 Ines which are presumably the strongest. Evidently, the absorption of the large number of smaller lines is not lost, 1 t w11l be considered in a separate paper.

\section{Results and Discussion}

As expected, the pressures in these are considerably lower than in hellumrich configurations ( Kapranides and Bohm, 1982), but with $\mathrm{P}_{\mathrm{g}}>10^{6} \mathrm{dyn} / \mathrm{cm}^{2}$ at $\tau=1$ for all models they are always much higher than e.g. In the corresponding layer of hotter maln sequence stars and lead to very strong line broadening and molecule formation. 

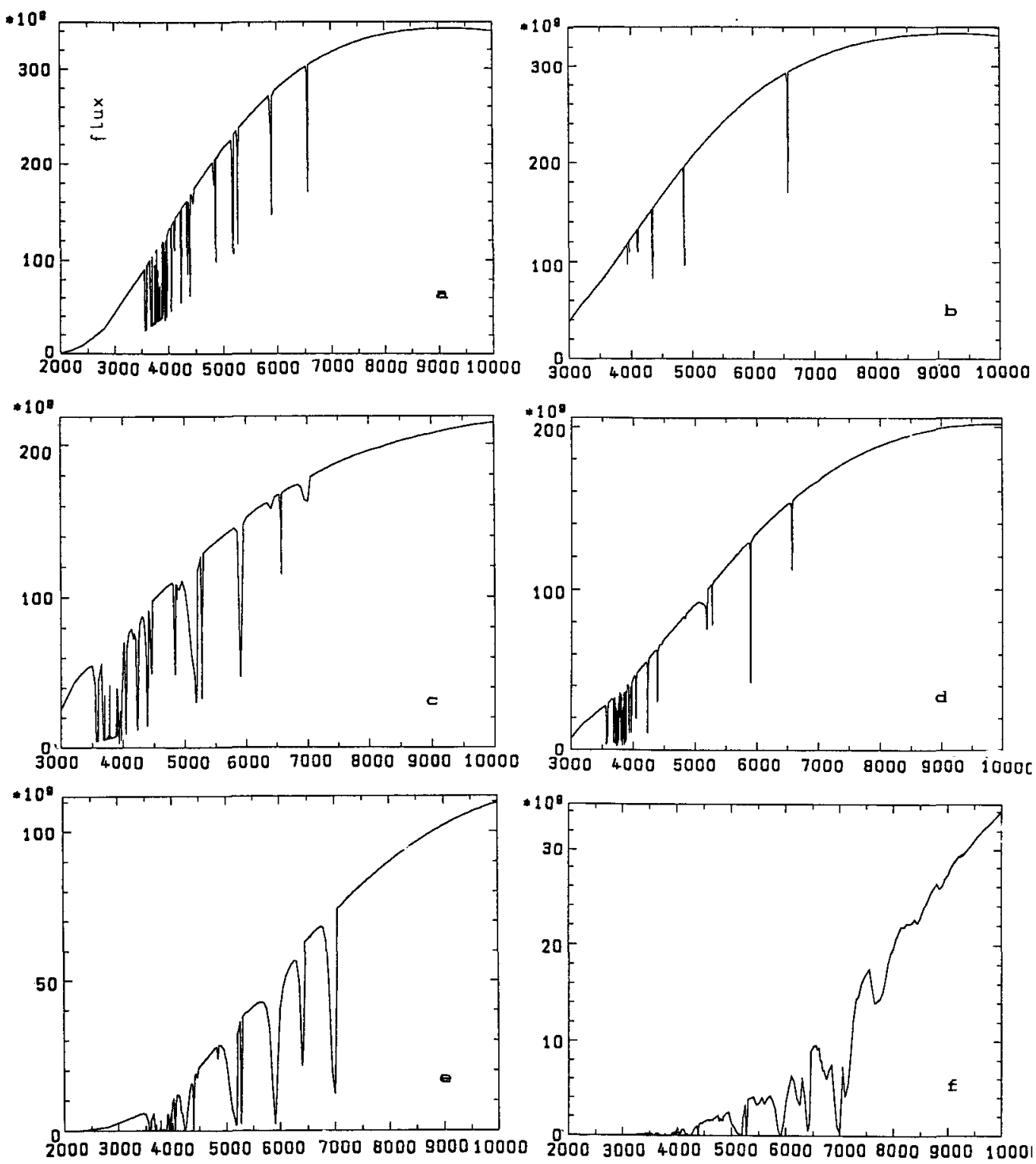

Wavelength (A)

Fig. 1. Examples for calculated spectra: a) $\mathrm{T}_{\text {eff }}=6000 \mathrm{~K},[\mathrm{Fe} / \mathrm{H}]=-2, \log \mathrm{g}$ $=8$; b) $\mathrm{T}_{\text {eff }}=6000 \mathrm{~K},[\mathrm{Fe} / \mathrm{H}]=-6, \log \mathrm{g}=8$; c) $\mathrm{T}_{\text {eff }}=5000 \mathrm{~K},[\mathrm{Fe} / \mathrm{H}]=-2, \log \mathrm{g}$ $=8$; d) $\mathrm{T}_{\text {eff }}=5000 \mathrm{~K},[\mathrm{Fe} / \mathrm{H}]=-4, \log \mathrm{g}=8$; e) $\mathrm{T}_{\text {eff }}=4000 \mathrm{~K},[\mathrm{Fe} / \mathrm{H}]=-2, \log \mathrm{g}$ $=8$; f) $\mathrm{T}_{\text {eff }}=2800 \mathrm{~K},[\mathrm{Fe} / \mathrm{H}]=-2, \log \mathrm{g}=5$. 
For some models with intermedlate parameters we encounter severe difflculties to converge the temperature stratification. We suspect that in the coolest parts of these atmospheres the sudden appearance of water vapor causes an ambigulty in the solution for $T(\tau)$ similar to that found for CO In the outer solar photosphere (cf. Muchmore et al. 1988), but that it is our case much harder to control because the convection is strong and reaches to rather low depths. However, several tests are still needed to confirm this hypothesis.

The calculated spectra ( for a few examples see Fig. 1 ) have the following characteristics:

(1) For effective temperatures $5000-6000 \mathrm{~K}$ and $[\mathrm{Fe} / \mathrm{H}]>-5$ metal Iines dominate; the $\mathrm{H} \alpha$ line is the only Balmer line still visible at $\mathrm{T}_{\text {eff }}=5000 \mathrm{~K}$. (11) Even for $[\mathrm{Fe} / \mathrm{H}]=-6$ a few strong metal lines are still visible.

(111) For effective temperatures of $4000 \mathrm{~K}$ and below molecular bands prevall. They make the spectra of white dwarfs and red subdwarfs of some lower temperatures to appear qualitatively rather simllar.

(1v) Quasi-static van der Waals broadening is not important for most Iines for these parameters, however a moderate increase in the damping constants and/or gravities suffices to change this conclusion.

\section{References:}

Greenstein, J.L, 1984, Astrophys, J, 276,602

Kapran1des, S., B8hm, K.H. 1982, Astrophys. J. 256, 227

Koester,D. 1987, Proc. IAU Coll. 95, Davis Phillp,A.G., Hayes, D.S.,

Llebert, J.W. , eds. 1987, p. 329

Llebert, J. 1980, Ann. Rev. Astron. Astrophys. 18, 363

Liebert, J., Wehrse, R., Green, R.F. 1987, Astron. Astrophys, 175, 173

Math1sen,R. 1984, Inst. of Theoret. Astrophys. Univ. Oslo, Pub. 1

Muchmore,D., Kurucz, R.L., Ulmschnelder,P. 1988, Astron. Astrophys. 201, 138

Traving.G. 1960, Uber die Theorle der Druckverbre1terung, Verlag Braun, Karlsruhe.

Wehrse, R. 1975, Astron. Astrophys, 39, 169

Wehrse, R. 1981, Mon. Not. Roy. Astron. Soc. 195, 553

Winget, D.E., Hansen, C.J., Llebert, J., van Horn,H.M. ,Fontalne,G. , Nather,

R.E., Kepler,S.O., Lamb,D.Q. 1987, Astrophys. J. 315,L77

Winget, D.E., van Horn, H.M. 1987, Proc. IAU Coll. 95, Dav1s Philip, A.G.,

Hayes, D.S., Liebert, J.W. , eds. 1987, p. 363

Ze1dler-K.T.,E.-M., Weldemann,V., Koester,D. 1986, Astron. Astrophys.

155,356 